\title{
COLLABORATION AS A ROUTE TO SME COMPETITIVENESS ${ }^{1}$
}

\author{
Francesco Adamo*
}

\subsection{A multiplicity of choices}

Geography and the history of economics teach us firstly that economic progress, growth and development involve multiple prime causes, entrepreneurial management styles, territorial production and distribution organisation and secondly that such processes occur in different ways since the Earth is an environmental space, physically and socially differentiated by the history of nature and peoples.

These statements may be rather peremptory and commonplace, but I should like first of all to deflate some myths of our times that stem from a rooted if not Manichean dichotomic view of the world. Three contrasts should be eliminated before attempting to properly define industrial policy lines and the analyses required for their implementation: large and small size enterprises; spatial concentration and diffusion; exogenous and endogenous development.

Firstly, I believe we can say that only large enterprises were formerly considered at academic and political levels since they were viewed as the only prospect for development, while today's only concern is small enterprises. Some underscoring of either's importance is certainly understandable historically but we should never forget that no alternative exists between the two, since both are essential for any country's economic growth and development even though their relative weight and strategic importance change in different production areas, with demand and supply structure and geographic market size. Economic progress in fact generally comes from the integration of different enterprises.

Secondly, territorial concentration and the dissemination of economic activities (centralisation versus decentralisation) do not necessarily follow one another in time; they are selective and often simultaneous processes.

Some economic activities tend to expand and others to concentrate in different historical moments according to the business and production cycle size and functions of each. Either process can prevail both in company numbers and geographical distribution. Concentration prevailed in Italy and Europe till the end of the Sixties; decentralisation both in industry and company services as well as in family dwellings and services became rampant from 1970 to 1990. New industrial activities and rare company services concentrated in a decreasing number 
of increasingly developing central areas during the past decades, marked by decentralised development and local independent growth.

Lastly, the theory of endogenous or selfcentred local development based on local markets, resources and forces is certainly opposite but not alternative to exogenous or extrovert development. The latter must somehow translate into a self-propelling process for it to last and generate real local economic progress. External demand- oriented and mainly external investment-generated production growth must engender local income and demand growth to make investment in new production profitable and suitable to satisfy new demand. Historically generated conditions regarding the socio-cultural milieu, rather than the physical ones brought about by relatively fast changes such as new infrastructures and services, are needed to make extrovert development introverted and consolidated, as well as a social structure capable of enhancing and stimulating individual initiative to create local entrepreneurship in particular.

Endogenous development is not only unthinkable without some export base, however. It never leads to durable growth and local socioeconomic progress without creating external demand of its own to guarantee the region plays its own competitive role in the geographic division of global labour and to make it attractive for outside investment. The different importance of the exogenous and endogenous factors marking the two models essentially holds true during the initial steps of the process; it depends on the conditions both of the local and specific world markets for the products the process is based upon.

Pluralistic views of the way to economic progress, its actors and territorial models no longer belong to economic geographers, traditionally inclined to underscore territorial peculiarities and differences; they are shared by analytical social science experts such as sociologists and economists, particularly by those who have cultivated these disciplines in application terms and have discovered the territory.
According to GIACOMO BECATTINI (1987), one of Italy's leading experts on the issues of local SME systems (1), this convergence stems from empirical studies of regional systems and was possible because "both parties tend to consider local, regional, national and international systems as subsystems inside vaster territorial systems" This convergence is certainly a matter for satisfaction on the one hand but is the cause for some concern on the other. I fear that recognition of unshakeable geographical diversity might lead to foregoing the basic functions of giving rules that are traditionally specific of economics but are also considered as a duty for other social sciences as well as geography.

This is why our contribution to this research programme does not attempt to use our studies on the Italian and other cases for drawing models automatically exportable elsewhere but at least to present some methods and procedures, concepts and industrial policy and analysis trends applicable to the CEECs considered.

This introduction chapter merely outlines the theses that are the main outcome of Italian research on small and medium size enterprises, that give a specific meaning to our participation in this programme.

The first thesis is that co-operation with other enterprises is the best way for small firms to be competitive for survival and growth. Such co-operation must be achieved mainly with other enterprises located in the same geographical area, that can vary according to space and economies of scale. A second thesis is that the birth, growth and competitiveness of a small size enterprise depend essentially on its vertical relationships with the local environment and the development conditions it offers. Briefly, global market competition needs local integration.

A distinction between direct co-operation with the intercompany exchange of information, capital, goods and persons and indirect co-operation through environments outside the enterprises themselves is in order here. The former can either be institutionalised with one of 
many legal forms of agreements and associations among companies, such as groups, consortia, co-operatives and the like or be the informal and simple expression of the division of labour that companies reach on the marketplace. Indirect co-operation among different companies can develop into a formal association to defend common interests, or remain an informal and unwritten agreement.

\subsection{From the enterprise to enterprise systems}

The premise that co-operation and/or integration with other enterprises and the local environment is one of the main competitive strengths small size enterprises can count on means not only that our research is mainly interested in concentrating on the relationships each enterprise enjoys with the local and global world outside it, but also focusing analytically and formally on the passage "from the enterprise to enterprise systems" from individual elements to the system, from company demography to local development and from competition between individual companies to competition between territorial systems.

Co-operation between enterprises does certainly not imply the need for a common territorial base. Associations and groups of multilocation enterprises exist, in the sense that individual enterprises making up such systems can be located in different places, towns, regions or countries. However, the small size enterprise we are concerned with here can only face up to world competition through strong local integration with other enterprises that coexist in the same area to take advantage of mutual economies of location and common urban services.

This contribution of Italian experiences on the survival and growth of enterprises uses a systemic geographical approach and it should be pointed out that special emphasis is on 1) the environment as a whole of external factors as indicated at figure 1 that illustrates the enterprise/environment interactions in the global local context and 2) on the structure of the enterprise system each individual company takes part in, where each company is prevalently integrated and can thus be taken as an element. The approach considers the geographical environment and the enterprise system as sub-system components of an ampler reality, the territorial system or Geosystem considered in this context as room for enterprise action and as a condition and product of their growth.

Integration of the enterprise into the local production and socio-economic context is basic for its competitiveness; the greater the environmental valences present on the territory, the greater the company's capability to relate with them. Environmental valences are defined as all the conditions stemming from elements present on territory where the company decides to be established; they range from natural resources to local growth management policies and from the presence of companies in the same or other businesses to the efficiency of transportation and communications infrastructures.

The following presentation of the results of analyses on the Italian case will dwell on cooperation rather than competition relationships between enterprises in the various production geosystem structures. The distinction between different local systems will concentrate on direct relationships between enterprises in the production process of a given product or service rather than the indirect relationships between local enterprises mediated by the environment, such as complementarity or competition obtained by using local labour, service, infrastructures and the like.

Many different types of co-operation and spatial integration models exist of course, as shown by the Italian experiences in the $4 \mathrm{sec}-$ tors chosen (foodstuffs, garments, furniture and the metalworking industry). 
Figure 1: Interactions between the enterprise, the local production system and geographical space and environment

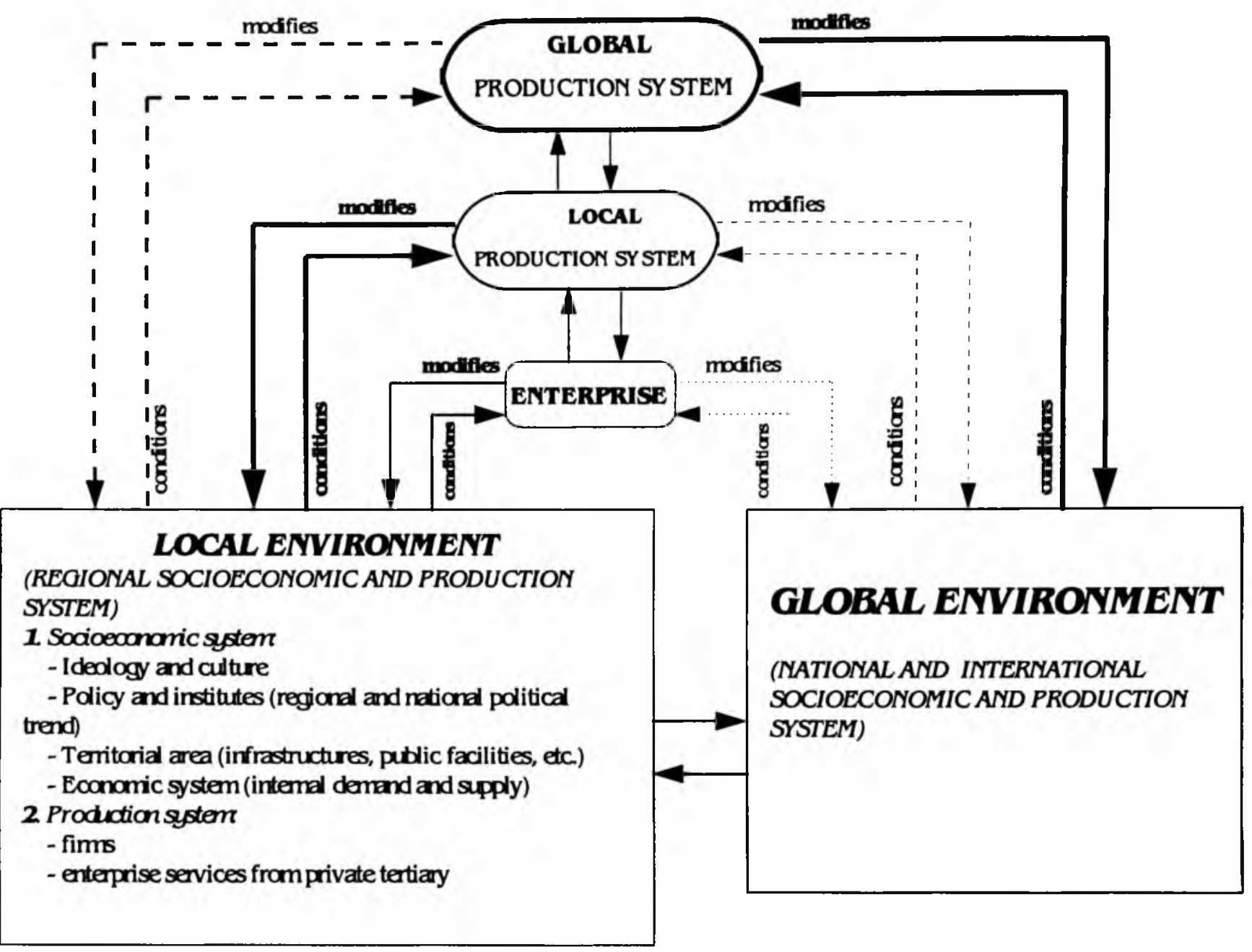

As a first approximation based on these sectorial analyses and other research work by the Authors, it can be stated that the main experiences of local development and industrial co-operation can be classed into one of the two previously mentioned models:

a) the Perroux development pole model, in which reality offers a wide range of variants and can also include multipole industrial complexes, and

b) the industrial district model, in which reality also offers many variants and Italian reality is very rich in, as internationally well-known (PICKE et al., 1991).
Both these organisation models can be seen and analysed as local regional industrial geosystems or industrial systems with a territorial basis as defined above; the most useful and valid theoretical grounds for SME competitiveness lies in contribution to external economies for both. The main difference lies in the system structure; namely a) the structure of a polarised system is tendentially made by dependence relations and b) the structure of a district system is basically made by interdependence relations.

As known, the first model of territorial organisation characterised the development of metal-working and chemical industries from the 
end of last Century to the beginning of the Seventies of this Century, dominated by great scale economy enterprises concentrated in the larger cities, which a myriad local small and medium size enterprises were subordinated to.

The industrial district is an organisational model mostly typical of the growth of traditional consumer goods producers in areas with old artisan traditions but also the recent development of modern industries producing highly specialised goods for small size markets, such as machinery for instance. The origins of this geosystem model sometimes date from industrialisation of last Century; it has been one of Italy's most vital and significant economic features for the last twenty years. The creation and expansion of industrial districts has not only boomed mostly in the northern and central areas of the country over the past decades with some spread to the south, given a greater importance of SMEs, but these firms (the typically district ones especially) has also greatly contributed to bringing about outstanding results in terms of Italian exports of industrial products, such as textiles, garments, footwear, furniture, machinery and the like.

It might be interesting to dwell on the essential features that define district and polarised systems as well as any spatial agglomeration of plant and manufacturing enterprises, before underscoring the more recent transformations that are somehow involving all local production systems, changing their structure and therefore forms of co-operation.

Broadly speaking, "industrial district" is an expression applied to any spatial agglomeration of small and medium size industrial enterprises; in the extreme, to the agglomeration of small size production units with the secondary attribution of being "sectorially" homogeneous as they produce the same or different goods to be used for assembling or producing the same end item. These agglomerations, which could be simply called SME industrial areas, are referred to by practically all the economic and geographic bibliography on Italian industrial districts, since no other criteria can be used in the absence of other available sources of information.

The concept of industrial district, as defined by ALFRED MARSHALL in 1879 and recently rediscovered in Italy by various experts, GIACOMO BECATTINI particularly (1987), is more interesting and useful both theoretically and in practical industrial policy use. Its main distinction in fact lies in its industrial structure and has therefore been assumed in this paper.

The integration relationships among district enterprises, as mentioned above, can be essentially considered as a joint interdependence, such as those which exist appropriately among equal partners This does not at all mean that all district enterprises are the same, that a purely technical labour division exists among them and they all have the same profit margin. Leader enterprises with their own trade marks and entertaining a direct relationship with the market exist inside the same district together with enterprises that only contract or subcontract individual components of the end item or even just assemble parts for third parties. The district does however contain several leader enterprises in competition with one another for selling the same end product on outside markets and even for purchasing inputs. This means individudal jobbers, contractors, subcontractors or independent individual operators are free to change customers, just as any enterprise producing end items or intermediates is free to find other local suppliers or workers.

Competition among district enterprises and independent workers is not however identifiable as a war of everybody against everybody else, which would be incompatible with cooperation and a certain degree of solidarity among the subject members of the district. It should rather be considered as the outcome of an objective value common to all the local system components, whereby "everyone incessantly tries to improve his or her individual or family status and.....no one can stand firm on produc- 
tion positions markedly below those prevalent on markets external to the district" (cf. BECATTINI, 1991).

Local competition is therefore certainly another essential tool for allowing the district and its individual enterprises to win the challenge of global competition. Inside the district it cannot however occur based only on calculations of mere economic conveniency; it is constrained by other social norms essential for reproducing and developing the system, first and foremost those that engender cooperation, the other basic district strength to face global competition.

These are the rules governing the existence of a local price system (for components, machinery, labour and money) separate from the one formed by competition on the global market, whereby local prices in particular fluctuate less than external ones. In other words, local market relationships are not mere exchanges as conceived on the basis of the so-called rationality of homo oeconomicus, since they cannot leave aside the needs of cooperation among district actors. This is direct cooperation by a myriad production and service enterprises, part-time and home workers that consists of integrated work division and therefore requires the decomposability into separate steps of production processes achieved in specialized units.

Small size, advanced specialization, ongoing training of highly qualified personnel and the existence of a market for efficient used machinery facilitate company proliferation during expansion phases.

Internal district co-operation also involves reproducing and developing the local milieu. District system actors certainly compete in exploiting the advantages pursuant therefrom but are aware of their common interest in reproducing the environmental values that allow the local system to operate and adapt them to the stimuli from the outside world. By far the most important environmental values are historical such as a certain common culture and mental attitude, a dowry of unspoken knowledge (cf. Becattini, 1994), the awareness of common interests for all district members leading to converging political choices and the local institutions playing an important supportive role for local enterprises, which are rooted the most in the territory and cannot be exported, rather than territorial elements such as basic infrastructures, production and labour training services, specific know-how and the like, that are exportable elsewhere to a certain extent.

Local public or private banking services certainly play a major role. Banks are an essential part of the district system; bank officers know their customers very well (just as everyone in the district knows everything about everybody else) and can even afford to assess risks based on an entrepreneur's real professional worth and not just on the basis of personal property.

From the strictly technical standpoint, classification of individual enterprises by operational or component specialisation is also achieved in other industrial geosystems, including those that satisfy the original version of the development "pole" model. Marked subordination in the horizontal integration relationships of small and medium firms with major companies is typical in this case however. Also, enterprises and their relationships are only profit-oriented, unlike the Central Italian district model as exemplified by BECATTINI $(1979,1987)$ and by G. FUÀ (1983); supplier companies have practically no relationships with one another, as is well expressed by PRIORE and SABEL's "solar system enterprise" (1984).

Furthermore, indirect co-operation through the environment is well-nigh non-existent, not only because of competition among suppliers but because the great enterprise dominating them in polarised systems is so politically strong as to exert direct influence on the institutions in order to at least reproduce the producible external economies it needs. 
A varied and complex range of different forms of industrial organisation, is being created between the Marshall's district model and the Perroux's pole model., following on the computer revolution, with the policy of development support that led to the proliferation of various types of scientific and technological parks, the popularity of various other infrastructures and services supporting the enterprise and employment, such as incubators, equipped areas and the like.

What matters more and should be stressed here is rather that the differences between the two integration forms are getting smaller. On the one hand, enterprises are integrating horizontally more and more and the relationships between leader enterprises and production or end consumer item suppliers tend to become more hierarchical in recession years particularly, for districts to face global competition and technical innovation and anyhow take on new forms that have little to do with Marshall-era districts; on the other, the trend to reduce enterprise size, disseminate flexible automation techniques and spread the formation of holdings companies and the organisation of groups where individual units enjoy increasing independence in large enterprise territorial systems is to be considered as the expression of the physiology of the new development model that is transforming pole or multipole geosystems into tendentially network ones, or anyhow into geosystems that have little to do with the Perroux model.

Despite these evolution trends on which we shall dwell in the following pages, it can be concluded that both system models still deserve attention for the political implications of their different structure.

The district in particular, conceived as the basic condition and product of co-operation and competition among enterprises and therefore their competitiveness too, deserves careful attention to identify some conditions of development from the bottom up as the enhancement of local resources and entrepreneurial skills, even though the initial stimuli for such a development can come from the outside, as often necessarily happens.

The ongoing deverticalization of large enterprise polarised systems achieved through the processes mentioned above, particularly the decentralisation of production segments that tends to create formally and more and more substantially independent enterprises that can also be small and medium size enterprises in some cases, can certainly be useful to orient the transformation of large CEEC public companies. The reorganisation into small and medium size company groups would not only give the flexibility and common strategy required to be competitive but would also facilitate privatisation.

\subsection{From flexibility to total quality: the diffusion of network structures}

At the end of the Eighties, when the crisis and restructuring of big enterprises began, most local SME production systems among the "local" development models (with a variable geographical scale territorial base) specialised in conventional sectors and were then quite rightly considered "leftovers" from the first industrial revolution, or even pre-industrial and proto-industrial craftsmanship industries; those that were expanding in the central and northeastern parts of Italy were classed as the expression of the development of "belated latteryear capitalism" typical of the Italian economy in Europe where the marginal areas used a throughwork backward process of filtering down and local revamping expressed by expansion accumulation to create "mature" or even obsolete activities, called economically marginal (ADAMO, 1979) and based on low labour costs and tax evasion. This industrialisation is connected with the so-called "submerged economy" or moonlighting. The same areas and the peripheral ones of north-western Italy witnessed 
the rapid creation of SMEs producing new, mainly small batch products with small markets, called interstitial.

Not much attention was given to the fact that these activities also produced plant, tooling and special machinery for the manufacturing industries such as printing, foodstuffs, footwear, furniture and the like, namely those capital goods that have proven to be particularly significant, though produced in small batches, and one of the most significant items of Italian exports.

The polar and multiple-pole great enterprise systems had stopped expanding during the Seventies, starting at Milan and Turin. The large enterprises reacted to the increasing difficulties of being competitive in the large metropolitan areas by choosing cost reduction; this is evident from the various reorganisation processes that started in Italy at the beginning of that decade, with 1) the relocation of complete production processes or parts thereof, 2) the transformation of companies into holdings and, 3) increasing production and service decentralisation, sometimes together with territorial relocation. This latter process ties up with Schumacher's slogan that "Small is beautiful" This became even more pertinent in the Italian case, as industrial districts were expanding all over central and northern Italy, with significant expansion towards the south and involving the outer areas of the space occupied by agglomeration economies of the larger towns. Some districts were the areas of traditional light industry that reorganised and consolidated on product and process quality, such as the textile districts of Biella and Prato, and other jewellery, footwear, furniture and tile districts that also coupled the production of capital goods to their speciality end items. Others completed their structures, others were born anew and were still in their initial steps.

The Italian SME-based industrialisation and ensuing urbanisation till the end of the Seventies were certainly the pathological expression of the crisis of large enterprises and cities on the one hand and of the delays in Italian capitalist development on the other.

The competitiveness of small industries both in prevalently endogenous and decentralised development areas was ultimately interpreted essentially by making resort to the concept of flexibility; the term "flexible specialisation" was in fact used to identify the whole new industrial development and organisation model in contrast with the oligopolistic capitalism or Taylorism that had been typical of industrial development and organisation respectively during the previous period (CRIVELLINI and PETTENATI, 1989).

These interpretations imply that the Marshall district model de facto already obsolete in the more advanced industrialised countries would have found all the ideal conditions to spread once again in the tendential saturation of markets during the recent economic phase that required great skill in differentiating products to satisfy the tastes of increasingly sophisticated and rich consumers, that is to say the flexibility afforded by small district enterprise size and more in general by the flexibility of labour to adapt to market fluctuations.

During the second half of the Eighties, the renewed competitiveness of large enterprise systems brought about by the increased use of the electronic innovations introduced during the Seventies was still interpreted in terms of socalled "flexible automation" The renewed competitiveness of large enterprises also underlined the interpretations of a pathological element of weakness in the Italian manufacturing industry, particularly those seeing SME districts specialising in traditional sectors as something destined to die out rapidly under competition from recently industrialised developing countries.

I believe it to be true that the weight of traditional sectors of the Italian economy is still excessive, is the expression of delays in its structure and is destined to diminish in real terms at least. Nothing however leads us to 
believe they will disappear, as is confirmed by the resistance of traditional manufacturing districts during the crisis of the early Nineties.

The reactions by many to the new competitive challenges starting from the second half of the decade would lead us to a different opinion. District structures and functions will certainly change a lot under the stimulus of increasing innovation and decentralisation of part of their production but will remain competitive thanks to these new developments. If Italian products remained competitive even during the recent recession, and in my view will continue to be competitive in the future, this is not so much due to their intimate flexibility nor to a greater propensity to innovate. A district's strength ultimately comes from the network structure of its internal relations and co-operation among its actors. Large enterprises are somehow attempting to imitate this structure, either by reorganising into relatively independent enterprise groups, or by internal work organisation and by developing their human resources and making them more responsible, guided by the strategic objective of Total Quality.

After all, quality achieved through cooperation and the circulation of ideas and knowledge is the foundation of the competitiveness that Italian districts enjoy.

The new thing that emerges from recent analyses, by the Bank of Italy on the ownership structure of Italian industrial enterprises particularly (BRUSCO, 1994), is the development of groups of small and medium size enterprises in which each company often maintains high margins of independence. Large enterprises are also going the same way, as we know, through a process of destructuring and reorganisation. As VACCÀ remarked (1994), leading transnational corporations are using "methods for organising their activities based on the decentralisation of production units, to enhance articulated decision-making processes by giving them greater independence, and transforming a large internationally dilated enterprise into a co-ordinated complex of small and medium size production units, each with decision-making responsibility especially qualified by direct individual operatormanager participation in defining the objectives each production unit is to give itself for contributing to the overall strategy of the large enterprise"

Another new thing that emerges from the analyses is that the trend towards the formation of network structures in which each node has a marked degree of decision-making independence is not merely an opportunistic legal and institutional measure to circumvent tax or labour relations rules and obtain sundry special terms. The group can effectively be interpreted as a new organisation and formal co-operation model suitable to respond to competition and company development problems, especially now when we must be able to manage increasingly high levels of complexity both inside and especially outside companies.

Just as in traditional districts, as indicated in the annexed bibliography, local large enterprise systems too have been introducing great changes over the past twenty years to such an extent that the original pole model no longer exists. The industrial systems typical of large towns and characterised by the Ford model until the end of the Sixties are also tending towards a network model and adopting some aspects of the district model, which ultimately explains their renewed vitality and physiological functionality.

With the process indicated above, the market globalisation and quality control now a highly strategic factor on more developed markets are leading companies to aggregate into simple or formal groups such as holdings organised into networks. The network structure can essentially develop starting both from poles and districts and replaces their structures when intercompany relationships explicity become formal co-operation.

The network (CIBIN et al., 1988) is a more suitable and flexible production organi- 
Figure 2: Pole and District Evolutions

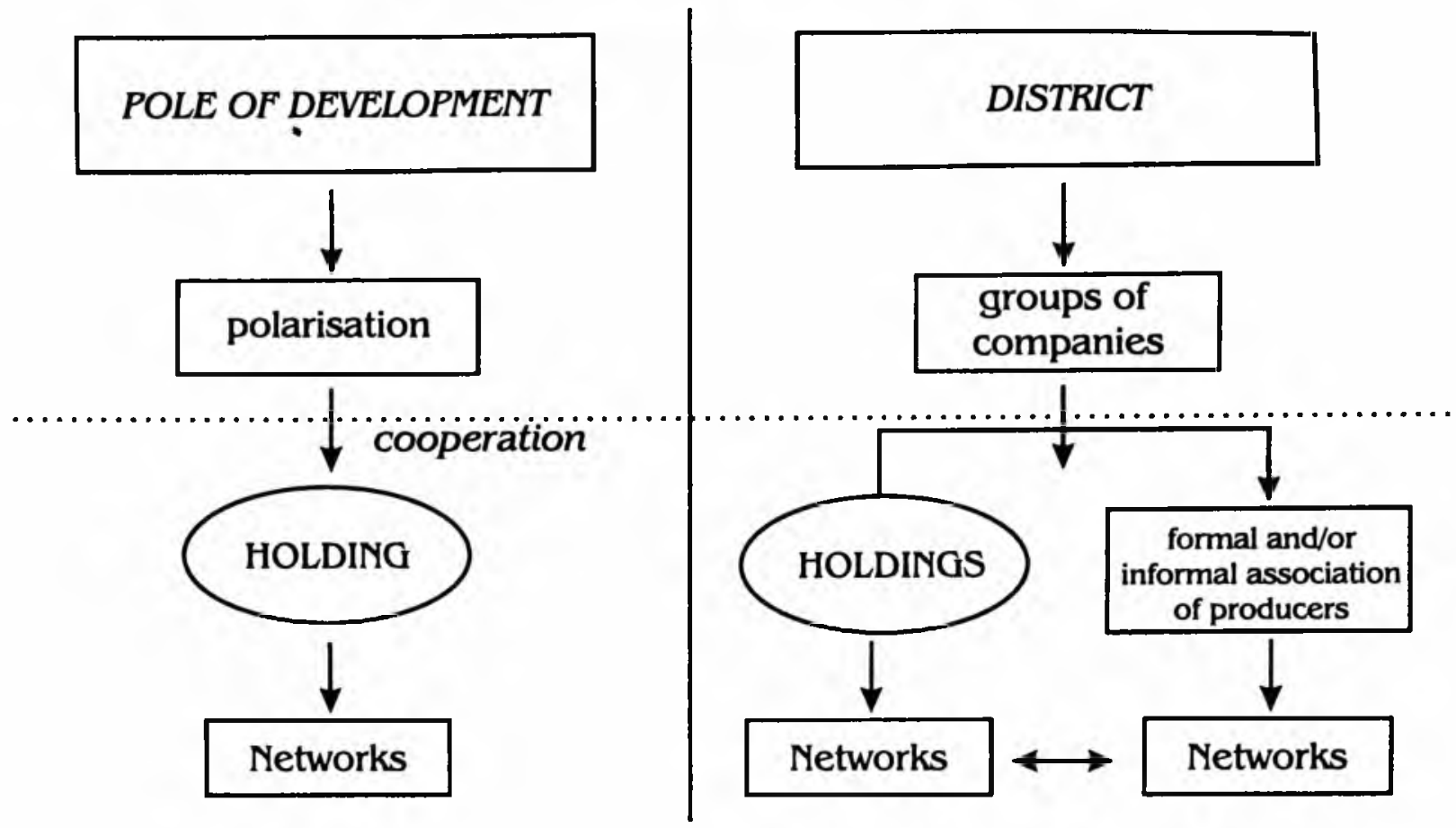

sation model that can appreciate the relationships between strategy and production structure better. Each network enterprise can survive autonomously from the others, can self-regulate itself and interact with the other companies with a result-oriented behaviour. In essence, the network represents all the strategic interdependencies defined and consolidated inside a group of enterprises not necessarily belonging to the same local system: typically, these interdependencies are oriented towards a common objective, so line integration is characterised by constant and continued introduction of new technology by individual companies specialising in given production steps or processes to achieve high product global quality and keep competitiveness high, more in general.

This networking process accentuates the variety of different local production systems by spreading in different ways and manners.

The taxonomy of these geosystems becomes more complicated when the fundamental variable of intercompany relationship structures considered so far is added on to by other variables such as production specialisation and degree and particularly the consideration of other processes which have intensified over the past decade and have mainly also involved most systems to different degrees: the growth of services to enterprises (notably the organisation or outright creation of scientific and technological parks) and the spreading of technical innovations such as telematics and information technology.

To properly analyse the results as presented in the following paragraphs, it is pointed out that conventional or modern local production systems integrating a technological park and districts in particular are normally classified by growth into: 1) embryonic (ADAMO, 1978) for concentrations of enterprises of the same business among which informal co-operation relationships, work specialisation and division and formal ones are still scant and not enough to offer a competitive edge; 2 ) simple or one-business when the local structure has already formed for final end products but enterprises 
still depend on outside sources for certain important inputs such as inconsumables or services, 3) consolidated when the area offers enterprises all essential services and the local industrial structure has an adequate subassembly of companies manufacturing the machinery used for the area's original specialisation; 4) complex and multi-sectorial when the business induced by machinery production have become at least as important and export base as the original specialisation and have in their turn originated new production specialities, such as other machine types no longer connected with the area's original specialisation.

\subsection{Patterns of collaboration between enterprises}

The relationships among enterprises have many changing forms, even inside the same business and local production system. They can be classed into:

a) informal co-operation, such as the simple supply of goods or services via the market, consisting of a normal sales and purchasing relationship in which each party is free of any production constraint and is totally free to stipulate contracts with other parties;

b) jobbing and sub-contracting, which are formal co-operation relationships implying the stipulation of a written or verbal supply contract, binding on both parties, the contractor and the sub-contractor ${ }^{2}$;

c) association relationships, such as consortia, co-operatives and joint-ventures, which are formalised by stipulating company papers or associations whereby each partner holds substantial formal shares of the activity and whose contractual power remains unchanged whatever market conditions may be.

This paper cannot cover the vast range of association agreements and contexts for which the use of these co-operation tools is the most appropriate, so we shall only dwell on sub-contracting relationships, which are the commonest both in district and polarised systems, attempting to underscore their different valences.

Jobbing is a contractual formula which is normally distinct from sub-contracting, as the jobber either producing all an end item or taking part in some production step can be and generally is the owner of the tooling and equipment he uses but receives the raw or semi-finished materials from the contractor; no capital outlay is required for such purchases. The typical element of jobbing is the high incidence of labour costs and low technology use (except for some emerging cases of jobbers using highly innovative technological systems) for the operations supplied. These are generally small size artisantype businesses working for one or two different contractors that feel market trends very strongly (while sub-contractors can sometimes be even larger than their customers and even have several ones)

Jobbers normally perform finishing and assembly operations. Similarly to sub-contractors they can also be used to diversify supply and produce part of articles normally made by the contractors allowing the latter to cope with temporary peak demand. Today this function is leading to informal associations between jobbers and sub-contractors directed at excluding the prime contractor for products requiring no trademark support, such as kits for instance.

Sub-contracting is the commonest form of co-operation and satisfies consolidated needs for production decentralisation dictated by work division and specialisation. A company may be born as already decentralised or decentralise during its life due to strategic and market needs ${ }^{3}$.

The basic premise for creating a subcontract relationship is reliability ${ }^{4}$, namely the certainty of achieving (even with certain production steps completed outside the company) a product having a good quality standard; this is 
made possible by the guarantee offered by competition between small and medium enterprises both in the pole and in the district, which also generates strong company specialisation, or exclusion from the market.

The basic reasons for choosing decentralisation of some production steps in as follows, in order of imprtance: 1) cost reduction deriving from decreased financial commitment for managing certain machinery or special production steps; 2) the greater capability to cope with peak demand periods and increased production flexibility; 3) improved product quality due to specialisation.

Sub-contracting can involve: special operations normally performed by very small and normally jobbing enterprises; special components requiring the use of special machinery the prime contractor is not equipped with; special end products made of different materials such as wood, metal and the like; semi-finished and standard components; standard end items. Disregarding the commercial side of the merchandise supplied, sub-contractor companies can in essence divide into:

capacity supplier companies, in a position to cope with changing contract size and allow the prime contractor to cope with temporary demand changes, not just due to small size and great flexibility but also because they can interact with companies in other districts for higher added value productions that can absorb transportation costs;

speciality supplier companies, in a position to satisfy specific prime contractor production demands, often with specific skills and plant the prime contractor cannot be equipped with. Prime contractors normally have consolidated relationships with such enterprises due to the complementarity of their respective productions (SILVESTRELLI, 1979)

For most SME sub-contractors, stable sub-contracting relationships normally mean improvement through greater cost-awareness. im- proved products and better production organisation. They also mean lesser discretionary power in management choices and decreased attention to non-production functions such as marketing and the like, which are important factors for company growth, especially for satellite sub-contractor companies supplying most of their production to just one prime contractor customer.

Ad hoc investigation has shown that subcontractors are normally with specific factors in mind such as geographic proximity, punctual delivery times, product quality, low unit costs, flexibility in contract variability, innovative and design capability present in most medium and large size sub-contractors and adequate production capacity (PIERACCIONI et al., 1995).

Sub-contracting is therefore a relationship which depends on the sub-contracting company production step; when the production step requires scant technical specialisation and low product quality, the sub-contractor's bargaining power with the prime contractor is constrained and the latter can dictate contractual terms, which means prime contractor dependency: when the sub-contractor is required to provide a high degree of specialisation and the availability of sophisticated technological plant subject to continued updating, its bargaining power increases and plays a highly strategic role with the prime contractor, which means sub-contractor dominance. Sub-contracting thus plays a strongly strategic role when it becomes irreplaceable for the prime contractor.

As mentioned earlier, contractors con act in a) interdependence and b) dominance-dependence condition in sub-contracting relationships.

Prime contractor dominance over the satellite sub-contractor occurs through the imposition by the former of technical and quality production standards and delivery times. The prime contractor is normally just one and decreased contracts can seriously jeopardise the satellite enterprise's existence. This is the typical instance of the development pole where there is just one prime contractor while the 
many sub-contractor companies are in fierce competition with one another.

An interdependence relationship between the capacity sub-contractor and the prime contractor can exist in more advanced polarised systems, mostly due to the former's medium or average size and its capability to relate with the latter to create a solid relationship based on common production criteria and quality objectives. The interdependence of a small size subcontractor is a strongly strategic growth and development factor: it becomes a source of ongoing technological innovation often stimulated by the prime contractors itself that demand the updating of production processes for improved production efficiency and product quality. Co-operation thus becomes an important tool for innovation and consequently a growth and development factor.
Even a small sub-contractor may enjoy dominance over the prime contractor, when it supplies special products with fast obsolescence hi-tech plant. In this case sub-contracting takes on such a strategic valence that the prime contractors has to accept sub-contractor conditions and guarantee an agreed-upon level of annual contracts and benefits in the for of services rendered to the sub-contractor to maintain and consolidate the relationship.

All the types of relationships mentioned above exist in the district, which is characterised by the co-presence of several prime contractors and greater freedom of choice for sub-contractors, even though the trend is towards interdependence that is strategically more effective than dominance, since the sub-contractor has more chances of expression and therefore to develop it human and technical resources.

\section{Notes}

1 Contribution to EU ACE Phare Research Project on The survival. Growth and Support Heeds of Manufaturing SMEs in Poland and the Baltic States: Developing a Policy Agenda, coord. by D. Smallbone, Middlesex University, London, 1996.

2 Given the vastness of the topic, we shall only underscore that co-operation agreements today are still supported by written or verbal contacts only based on mutual contracting party trust. In short, they are non equity agreements, as each party retains complete bargaining autonomy. The formula of equity agreements is however becoming more popular, that is relationships based on shareholding by the underwriters in sub-contractor capital with the consequence of producing new virtual integration of contractors, leaving ample contractual autonomy to sub-contractors versus other companies.
3 The choice of decentralising production, by disintegrating it vertically and jobbing various production steps of segments to outside suppliers in other words, is in fact neither obligatory nor pure chance. It depends on the ratio between the socalled transaction and co-ordination costs borne by the company. As known, the former are costs the company encounters in the event of decentralisation or externalisation of one or more production steps; the latter are tied to management of the production process inside the company itself. The company opts for decentralisation when co-ordination are higher than transaction costs or concentrates production by integrating its different steps.

4 "The search for reliability is synthesised by process and/or product quality, timeliness and adaptation to and/or correspondence with contractor demands" (PIERACCIONI et. al., 1995, p.49). 


\section{Bibliographic}

ADAMO, F. Una Periferia Industriale nell'Italia di Nord-Ovest. La Provincia di Alessandria. Alessandria: Dell'Orso, 1979.

BECATTINI, G. Dal Settore Industriale al Distretto Industriale. Alcune Considerazioni sull'Unità d'Indagine dell'Economia Industriale. In: Rivista di Economia ePolitica Industriale, n.1, 1979.

BECATTINI, G. II Distretto Industriale Marshalliano: Cronaca di un Ritrovamento. In: BECATTINI, G. (Ed.). Mercato e Forze Locali: il Distretto Industriale. Bologna: II Mulino, 1987.

BECATTINI, G. Il Distretto Marshalliano Come Concetto Socio-economico. In: PYKE, F.; BECATTINI, G.; SENGENBERGER, W. (Eds.). "Distretti Industriali e Cooperazione fra Imprese" In: Italia in Studi e Informazioni. Quaderni 34, Firenze, Banca Toscana, 1991.

BRUSCO, S. Una Ricerca della Banca d'Italia Sulle Caratteristiche dell'industria Manifatturiera Italiana. In: Economia e Politica Industriale, n.83, 1994,

CIBIN, R.; FAllaNi, S. La Rete, Quale Nuova Modalità Interorganizzativa nei Processi di Creazione di Imprenditorialità. In: Piccola Impresa/Small Business, n.2, 1988.

CRIVELlini ; PETTENATI, P. Modelli Locali di
Sviluppo. In: BECATTINI, G. (Ed.). Modelli Locali di Sviluppo. Bologna: Il Mulino, 1989.

ESPOSITO, E.; RAFFA, M. Subcontracting: A Microanalytical Approach. I.C.S.B. 39th World Conference, Strasbourg, June 2729, 1994.

FUÀ, G. L'Industrializzazione del Nord-Est e del Centro. In: FUÀ, G.; ZACCHIA, C. (Eds.). Industrializzazione Senza Fratture. Bologna: II Mulino, 1983.

PYKE, F.; BECATTINI, G.; SENGENBERGER (Eds.). Industrial Districts and Inter-firm Co-operation in Italy. Geneva: International Institute for Labour Studies, 1990.

PIERACCIONI, L.; ESPOSITO, G.F. I Sistemi Localied i Collegamenti Produttivi tra le Imprese. In: Sinergie, n.36-37, 1995.

PIORE, M.J.; SABEL, C.F. The Second Industrial Divide. Possibilities for Prosperity. New York: Basic Book, (1984),

SILVESTRELLI, S. I Rapporti di Subfornitura nell'Industria dei Mobili. In: Economia $e$ Politica Industriale. Milano: Franco Angeli, n.23, 1979.

VACCÀ, S. Sviluppo Locale e Mercato Globale: tra Passato e Futuro. Workshop on Suiluppo Locale e Mercato Globale. Artimino, 12th-17th sept., 1994. 